\title{
CURRÍCULO INTEGRADO E PRÁTICAS PEDAGÓGICAS NOS IFs: MAPEAMENTO DE PESQUISAS EM BASES DE DADOS
}

\section{Integrated Curriculum and Pedagogical Practices in the Federal Institutes (Ifs): Mapping Researches in Databases}

\author{
Samai Serique dos Santos Silveira* \\ Silvana Neumann Martins **
}

\begin{abstract}
Resumo: O presente artigo refere-se ao recorte de uma investigação que está em desenvolvimento na Universidade do Vale do Taquari - Univates/RS. Teve como objetivo mapear pesquisas que tratam sobre currículo e práticas pedagógicas integradoras nos Institutos Federais de Educação, no período que compreende os anos de 2014 a 2018. Para tanto, trabalhou-se com a abordagem qualitativa e a análise documental. Foram selecionadas quatro fontes para a coleta de informações, a saber: a Base de Dados de Dissertações e Teses da Coordenação de Aperfeiçoamento de Pessoal de Nível Superior (CAPES), o Portal de Periódicos da CAPES, o Grupo de Estudos e Pesquisa sobre Trabalho e Educação (GEPTE) e uma obra lançada no I Seminário Nacional do Ensino Médio Integrado, a qual reúne pesquisas na Rede Federal, em diferentes estados do Brasil. A partir do material analisado, permite-se concluir que diversas práticas podem traduzir a integração curricular, sob diferentes perspectivas teóricas e que muitas alternativas integradoras foram evidenciadas em variadas experiências pedagógicas.
\end{abstract}

Palavras-chave: Práticas Integradoras. Instituto Federal de Educação. Ensino Médio.

\begin{abstract}
This article focuses on the part of an investigation being carried out at the Universidade do Vale do Taquari. It aimed to map researches about curriculum and integrating pedagogical practices in the Federal Institutes of Education between 2014 and 2018, through qualitative approach and documentary analysis. Four sources for information collection were chosen: the Database with Theses and Dissertations of the Coordination for the Improvement of Higher Education Personnel (CAPES), CAPES Journal Portal, the Group of Study and Research on Work and Education (GEPTE) and a work released in the $1^{\text {st }}$ National Seminar for the Integrated Secondary School, which presents research in the Federal Network, in distinct states of Brazil. The material analyzed allows us to conclude that a variety of practices may depict curriculum integration, in light of diverse theoretical perspectives, as well that numerous integrating alternatives were evidenced in various pedagogical experiments.
\end{abstract}

Keywords: Integrating Practices. Federal Institute of Education. Secondary School.

\footnotetext{
* Doutoranda no Programa de Pós-graduação em Ensino da Univates/RS. Pedagoga no Instituto Federal de Educação, Ciência e Tecnologia do Pará. Bolsista CAPES. https://orcid.org/0000-0003-0883-0036. E-mail: sserique@hotmail.com.

** Doutora em Educação pela PUC/RS. Docente Permanente nos Programas de Pós-graduação em Ensino e Mestrado Profissional em Ensino de Ciências Exatas da Univates/RS. https://orcid.org/0000-0003-1944-3760. Email:smartins@univates.br.
} 


\section{Introdução}

No Brasil, desde a década de 1990, o Ensino Médio tem sofrido mudanças. O cenário das políticas educacionais implementadas a partir do governo de Fernando Henrique Cardoso (1995-2002) culminou com a institucionalização dos Parâmetros Curriculares Nacionais para o Ensino Médio (BRASIL, 1999). Posteriormente, a partir do Governo Lula (2003-2010), Dilma Rousseff (2011-2016) e, nos anos (2016-2017), no de Michel Temer, foram aprovadas diferentes alterações. Neste último, foi modificada a Lei de Diretrizes e Bases da Educação Nacional (LDB) $n^{\circ}$ 9.394/96, por meio da Lei $n^{\circ} 13.415 / 2017$, a qual apresenta a formação técnica e profissional como um dos itinerários formativos para o currículo do Ensino Médio.

Referindo-se ao Ensino Médio nos Institutos Federais (IFs), a Lei no 11.892/2008, que criou os Institutos Federais de Educação, Ciência e Tecnologia, a Resolução nº 6/2012, que define as Diretrizes Curriculares Nacionais para a Educação Profissional Técnica de Nível Médio e a nova Lei do Ensino Médio n ${ }^{\circ} 13.415 / 2017$, contemplam a perspectiva da integração nesse nível de ensino. Especificamente nos Institutos Federais temos diferentes experiências que possibilitam novos olhares sobre o ensino médio integrado. Sobre tal problemática, apresentamos, neste artigo, o mapeamento de pesquisas em diferentes fontes que tratam sobre currículo e práticas pedagógicas integradoras nos Institutos Federais de Educação, no período que compreende os anos de 2014 a 2018.

A seguir, apresenta-se a compreensão de currículo integrado que tem norteado os Institutos Federais de Educação, buscando refletir sobre os fundamentos epistemológicos que sustentam essa proposta pedagógica, visando a superação da dualidade que historicamente tem constituído a educação profissional.

\section{Concepção de currículo integrado}

Ramos (2008), em defesa da escola unitária pública e visando a superação da separação entre trabalho intelectual e manual, destaca o caráter ético-político do tema. Parte-se da premissa que existe uma concepção de mundo e sociedade que sustenta essa forma de conceber a educação para os trabalhadores e compõe uma luta junto a projetos societários distintos no interior da sociedade brasileira. Nessa perspectiva, a autora destaca:

\footnotetext{
A concepção da escola unitária expressa o princípio da educação como direito de todos. Uma educação de qualidade, uma educação que possibilite a apropriação dos conhecimentos construídos até então pela humanidade, o acesso à cultura, etc. Não uma educação só para o trabalho manual e para os segmentos menos favorecidos, ao lado de uma educação de qualidade e intelectual para o outro grupo. Uma educação unitária pressupõe que todos tenham acesso aos conhecimentos, à cultura e às mediações necessárias para trabalhar e para produzir a existência e a riqueza social (RAMOS, 2008, p. 2).
}

A partir dessa concepção, afirma-se que a educação pode romper com a visão dual, possibilitando a todos o direito aos conhecimentos construídos pela humanidade, além do acesso "[...] à cultura, a ciência, ao trabalho, por meio de uma educação básica e profissional" (RAMOS, 2008, p. 3), na perspectiva da construção e consolidação do currículo integrado.

Nesse contexto, concebe-se o currículo integrado não apenas como forma, mas também como conteúdo. Para clarear a concepção aqui defendida, parte-se da compreensão apresentada por Ramos (2008, p.3), que atribui três sentidos ao conceito de integração: “[...] como 
concepção de formação humana, como forma de relacionar ensino médio e educação profissional e como relação entre parte e totalidade na proposta curricular".

O primeiro sentido atribuído a ele diz respeito à formação omnilateral. De caráter filosófico, concebe o ser humano no processo formativo, a partir da integração das diferentes dimensões da vida, possibilitando-lhe a formação unitária. Tais dimensões caracterizam-se como o trabalho, a ciência e a cultura, todas integradas e fundamentais no desenvolvimento dos sujeitos, mediados pelas práticas sociais.

Em relação ao trabalho, esse é inerente ao ser. No sentido ontológico, compreende a realização humana, é interação, criação, "[...] para a satisfação de necessidades e produção de liberdade" (RAMOS, 2008, p. 4), não caracterizando ainda, como atividade econômica específica.

Já o trabalho, enquanto categoria histórica, é prática econômica, modo de produzir, vendendo a força de trabalho no interior de um modo de produção, mantido por relações sociais específicas. Portanto, consideramos o trabalho enquanto categoria histórica e como realização humana. "[...] Esse sentido estrutura as práticas de profissionalização, de formação profissional como preparação para o exercício do trabalho. Mas esta é somente uma dimensão do trabalho [...]" (RAMOS, 2008, p. 4).

Desse modo, o trabalho pode ser compreendido como realização humana e produção da existência, pois caracteriza-se como um princípio educativo, que pode levar à emancipação dos sujeitos e considera a base da existência humana. Assim, o trabalho como princípio educativo possibilita a construção coletiva da realidade, de maneira crítica, considerando as determinações sociais e construindo um projeto contra-hegemônico que busque superar o individualismo e a exclusão social, criando e recriando, "[...] pela ação consciente do trabalho, pela cultura e pela linguagem, a sua própria existência" (FRIGOTTO; CIAVATTA; RAMOS, 2005, p. 17).

A segunda dimensão da formação humana, refere-se à ciência, mediada pela ação humana e pelo trabalho, produzindo os conhecimentos "[...] que se tornam legitimados socialmente como conhecimentos válidos porque explicam a realidade e possibilitam a intervenção sobre ela" (RAMOS, 2008, p. 4). Portanto, à medida que o ser humano interage e produz, apropria-se da natureza e cria realidades, transformando-as para atender suas necessidades.

Sobre a terceira dimensão, a cultura, pode-se dizer que é construída socialmente e nos guia a partir dos valores éticos e estéticos às práticas sociais, agindo de forma coesa ao grupo social ao qual pertencemos. Assim, as três dimensões de integração entre trabalho, ciência e cultura são concebidas indissociavelmente, pois colocam o ser humano como construtor, sujeito da sua realidade, podendo, assim, transformá-la.

Retomando a discussão, o segundo sentido da integração trata sobre a indissociabilidade entre educação profissional e educação básica. Ramos (2008) evidencia que o trabalho do ponto de vista econômico configura-se como uma necessidade para a profissionalização dos jovens trabalhadores e que essa juventude, em razão das condições socioeconômicas, não pode adiar sua profissionalização para após a conclusão da educação básica e/ou ensino superior. No sentido de contribuir com relação à essa questão, a pesquisa realizada por Simões $(2007$, p. 84) destaca:

O ensino técnico articulado com o ensino médio, preferencialmente integrado, representa para a juventude uma possibilidade que não só colabora na sua questão da sobrevivência econômica e inserção social, como também uma proposta educacional, 
que na integração de campos do saber, torna-se fundamental para os jovens na perspectiva de seu desenvolvimento pessoal e na transformação da realidade social que está inserido. A relação e integração da teoria e prática, do trabalho manual e intelectual, da cultura técnica e a cultura geral, interiorização e objetivação vão representar um avanço conceitual e a materialização de uma proposta pedagógica avançada em direção à politecnia [...].

Dessa forma, a integração entre a formação geral e a formação técnica propiciará o acesso ao saber cultural sistematizado ao longo das gerações, possibilitando aos jovens inseridos nas escolas públicas a possibilidade de visão ampliada sobre as relações estabelecidas nos processos de trabalho, além do conhecimento geral sobre a cultura e a ciência.

Dando prosseguimento às discussões, o terceiro sentido trata sobre a integração de conhecimentos gerais e específicos como totalidade curricular. O que isso significa? Não se trata de justaposição, somatório de conhecimentos, o desafio é maior, "É uma outra postura epistemológica, "[...] que se exige, recorrendo a princípios e pressupostos da interdisciplinaridade e da visão totalizante da realidade" (RAMOS, 2008, p. 20). Tal currículo considera a historicidade dos fenômenos da sua própria realidade, da ciência e do trabalho, situando os conhecimentos produzidos no decorrer da história da humanidade, considerando a dinâmica social de produção. Assim,

[...] o currículo do ensino médio integrado - destaca a organização do conhecimento
como um sistema de relações de uma totalidade histórica e dialética. Ao integrar, por
um lado, trabalho, ciência e cultura, tem-se a compreensão do trabalho como
mediação primeira da produção da existência social dos homens, processo esse que
coincide com a própria formação humana, na qual conhecimento e cultura são
produzidos. O currículo integrado elaborado sobre essas bases não hierarquiza os
conhecimentos nem os respectivos campos das ciências, mas os problematiza em suas
historicidade, relações e contradições (CIAVATTA; RAMOS, 2012, p. 309-310).

Diante do exposto, pode-se concluir que o desenho do currículo integrado constitui um desafio às instituições que se propõem a efetivar essa proposta, pois demanda clareza na concepção pedagógica adotada. Isso implica mudanças nos processos de ensino, focado no sujeito que aprende.

Nessa perspectiva, entre as pesquisas selecionadas neste trabalho, destacam-se as diversas experiências desenvolvidas nos Institutos Federais e que estão sistematizadas na obra de Araújo e Silva (2017). Nessa obra, percebeu-se que diferentes concepções teóricas têm norteado os currículos nos IFs, tais como a teoria da complexidade, pragmatismo, pensamento pós-moderno, mas predominantemente encontraram-se pesquisas fundamentadas no marxismo, tendo como principais interlocutores Frigotto, Ciavatta e Ramos (2005), Kuenzer (2007, 2009) e Saviani (2007).

Destacam-se, também, algumas incoerências em que os autores pesquisados embasam suas investigações em pensadores com posições contraditórias, indo de encontro à concepção de currículo integrado defendido pela Rede Federal, principalmente após a Lei n ${ }^{\circ}$ 13.415/2017, que trata da Reforma do Ensino Médio.

Evidencia-se, assim, a complexidade na construção do ensino médio integrado e, ao mesmo tempo, a importância da implementação de aspectos que aparecem como relevantes no desenvolvimento em torno da ideia de integração, tais como: o caráter emancipatório da 
proposta do ensino técnico integrado ao ensino médio; compromisso coletivo e democrático entre os sujeitos que compõe os IFs; reconhecimento dos avanços e contradições na implementação da proposta; reconhecimento da multiplicidade de culturas que circulam no espaço institucional, espaço e tempo para o planejamento, execução e avaliação; trabalho coletivo visando integrar conteúdo e forma e formação continuada.

\title{
3 Práticas Pedagógicas
}

A escola, como instituição partícipe da sociedade, constitui-se na dinâmica das relações sociais. Para compreendê-la, faz-se necessário conhecer os determinantes sócio-políticos, culturais e econômicos que a engendram. Nesse sentido, a função social que a escola desempenha é destacada por Franco (1988, p. 57):

\begin{abstract}
O papel precípuo da escola é a transmissão de conhecimentos. Não conhecimentos enciclopédicos, abstratos, mas conhecimentos vivos e concretos, indissoluvelmente ligados às experiências de vidas dos alunos e às exigências históricas da sociedade presente. O papel da escola, pois, é fundamentalmente transmitir, de maneira lógica, coerente e sistemática, os conhecimentos acumulados historicamente pelo homem, ou seja, os conhecimentos científicos, tecnológicos, filosóficos, culturais, etc., indissoluvelmente ligados à experiência dos alunos e às realidades sociais mais amplas.
\end{abstract}

De acordo com o texto supracitado, são fundamentais práticas pedagógicas que se relacionem com o vivido dos alunos, a partir de uma construção coletiva, pautada em práticas sociais, tendo como objetivo primeiro a socialização dos saberes sistematizados historicamente. Nesse mesmo sentido, Saviani (2013, p. 14) evidencia também a função primeira da escola:

\begin{abstract}
A escola existe, pois, para propiciar a aquisição dos instrumentos que possibilitam o acesso ao saber elaborado (ciência), bem como o próprio acesso aos rudimentos desse saber. As atividades da escola básica devem organizar-se a partir dessa questão. Se chamarmos isso de currículo, poderemos então afirmar que é a partir do saber sistematizado que se estrutura o currículo da escola elementar.
\end{abstract}

Compartilhando dessas ideias apresentadas pelos autores, percebe-se a importância da escola na garantia do direito à educação e aos conhecimentos por meio de práticas pedagógicas críticas. Nesse sentido, esta precisa explicitar suas intencionalidades, como instituição social que tem uma função específica no seio da sociedade. Fora isso, é relevante evidenciar que a escola, enquanto espaço institucionalizado, é diversa, contraditória e síntese de múltiplas determinações.

Segundo Saviani (2019), é importante contextualizar duas perspectivas que têm orientado a educação brasileira e, consequentemente, a práxis pedagógica: a pedagogia com referência na filosofia pragmática e a pedagogia tendo como base a filosofia da práxis.

Como um dos principais representantes da filosofia pragmática na área educacional, John Dewey (1859 - 1952), ainda hoje, exerce influência em uma geração de professores. Tal filosofia parte do princípio de uma epistemologia “[...] que considera que seus fundamentos [...] estão centrados na questão lógico-metodológica da relação sujeito-objeto no processo de apreensão do real" (RAMOS, 2010, p. 90). 
Quanto à segunda concepção, recorremos às contribuições de Vasquez (1977, p. 5), o qual concebe a categoria práxis a partir do materialismo histórico-dialético. Para o autor, práxis constitui-se como "[...] categoria central da filosofia que se concebe ela mesma não só como interpretação do mundo, mas também como guia de sua transformação". E ainda, sobre essa mesma compreensão, enfatiza:

[...] entendemos a práxis como atividade material humana, transformadora do mundo e do próprio homem. Essa atividade real, objetiva, é, ao mesmo tempo, ideal, subjetiva e consciente. Por isso insistimos na unidade entre teoria e prática, unidade que implica também em certa distinção e relativa autonomia. A práxis não tem nada para nós um âmbito tão amplo que não possa inclusive englobar a atividade teórica em si, nem tão limitado que se reduza a uma atividade meramente material (VASQUEZ, 1977, p. 406).

Neste contexto, evidencia-se a importância da compreensão da práxis como atividade humana a partir da unidade entre teoria e prática, situando-a em contínua interação e ultrapassando a perspectiva fragmentária e unilateral, considerando os determinantes sociais existentes. Ainda sobre esse prisma, Konder (1992, p. 115) afirma:

\begin{abstract}
A práxis é a atividade concreta pela qual os sujeitos humanos se afirmam no mundo, modificando a realidade objetiva e, para poderem alterá-la, transformando-se a si mesmos. É a ação que, para se aprofundar de maneira mais consequente, precisa da reflexão, do autoquestionamento da teoria; e é a teoria que remete à ação, que enfrenta o desafio de verificar seus acertos e desacertos, cotejando-os com a prática.
\end{abstract}

A partir das duas perspectivas elencadas sobre as diferentes concepções que norteiam as práticas pedagógicas, optou-se pelos pressupostos da filosofia da práxis, pois entende-se que esta é quem melhor explica a complexidade da educação brasileira, considerando as questões sócio-políticas, econômicas e culturais específicas da conjuntura atual. Assim sendo, uma das críticas que a filosofia da práxis faz em relação à filosofia pragmática é quanto à racionalidade técnica, pois nesta última perspectiva, a atividade humana reduz-se à dimensão práticoutilitária, individualista e cientificista.

Franco (2012, p. 172) evidencia que quando “[...] nos referimos às práticas pedagógicas, estamos nos reportando a práticas sociais que se exercem com a finalidade de concretizar processos pedagógicos". Destarte, tendo como ponto de partida a concepção dialética de unidade entre teoria e prática e nos aproximando dos fenômenos educativos, como prática social, pode-se refletir então sobre o entendimento do que sejam práticas pedagógicas. Ainda nessa mesma compreensão, a autora assim se refere:

As práticas pedagógicas se organizam intencionalmente para atender a determinadas expectativas educacionais solicitadas/requeridas por uma dada comunidade social. Nesse sentido, elas enfrentam, em sua construção, um dilema essencial: sua representatividade e seu valor advém de pactos sociais, de negociações e deliberações com um coletivo. Ou seja, as práticas pedagógicas se organizam e se desenvolvem por adesão, por negociação ou, ainda por imposição. Por certo, essas formas de concretização das práticas produziram faces diferentes para a perspectiva científica da Pedagogia (FRANCO, 2012, p. 541). 
Esta concepção demonstra que as diferentes práticas pedagógicas podem ser manifestadas em diferentes formas e meios. E que uma das características fundamentais referese à intencionalidade da atividade, atribuindo-lhe sentido. As práticas pedagógicas são orientadas por enfoques epistemológicos que, muitas vezes, não estão claros para os sujeitos da ação educativa, tampouco compreendidas na sua multidimensionalidade, pois " [...] as práticas impõem posicionamentos, atitude, força e decisão" (FRANCO, 2012, p. 544).

Dentre os trabalhos pesquisados, destaca-se a discussão sobre os princípios do pragmatismo estarem presente de forma crítica na maioria das pesquisas. No entanto, encontraram-se práticas pedagógicas (PEREIRA, SANTOS e OLIVEIRA NETO, 2017) fundamentadas no pensamento pragmático, aprender fazendo, tendo Dewey como referência. Nesse contexto, Saviani (2013) refere-se a essa corrente pedagógica presente no ideário brasileiro de neoprodutivismo e suas variantes: neoescolanovismo, desconstrutivismo e neotecnicismo.

Tal concepção choca-se com a discussão que se tem construído na Rede Federal, no sentido não de oposição entre teoria e prática, mas na compreensão que rompe com a visão instrumental dos processos pedagógicos, que ainda se faz presente no cotidiano escolar e que, muitas vezes, apresenta-se com uma visão reducionista do "como fazer", sem situar o que, por que e para quem fazer. Nesse sentido, Candau (2007, p. 23) afirma que o processo de ensinoaprendizagem é multidimensional, ou seja, é permeado pela dimensão humana, técnica e político-social, pois "[...] procura partir da análise da prática pedagógica concreta e seus determinantes".

Nesta perspectiva, compreendendo as determinações na dinâmica da sociedade contemporânea, tem-se buscado contribuir com estudo e pesquisa nessa área, visando contribuir com práticas pedagógicas mais condizentes com a realidade da educação brasileira.

\section{Pesquisas mapeadas sobre o currículo integrado e práticas pedagógicas}

Primeiramente, selecionou-se a base de dados de dissertações e teses da Coordenação de Aperfeiçoamento de Pessoal de Nível Superior (CAPES), a qual representa a maior fonte de pesquisa sobre as produções da Pós-graduação no Brasil. No catálogo de teses e dissertações da CAPES/MEC, selecionamos o período de 2014 a 2018, a partir dos descritores "prática pedagógica integradora". O sistema apresentou 143 resultados. Destes, somente seis foram selecionados em razão da problemática da pesquisa e também por situar as práticas pedagógicas integradoras nos Institutos Federais de Educação, conforme descrito no Quadro 1.

Quadro 1 - Relação das teses encontradas no Catálogo da CAPES/MEC, no período de 2014 - 2018

\begin{tabular}{|l|l|}
\hline \multicolumn{1}{|c|}{$\begin{array}{c}\text { AUTOR(A) } \\
\text { ANO }\end{array}$} & \multicolumn{1}{c|}{ TESE } \\
\hline $\begin{array}{l}\text { MACHADO, E. R. } \\
2016\end{array}$ & $\begin{array}{l}\text { Mundo do trabalho e educação profissional: formação técnica em edificações no } \\
\text { Instituto Federal de Goiás - Campus Goiânia. }\end{array}$ \\
\hline $\begin{array}{l}\text { GUIMARAES, G. } \\
2017\end{array}$ & $\begin{array}{l}\text { A relação entre a educação e o trabalho na educação profissional técnica de nível médio } \\
\text { do IFG - Campus Goiânia: contradições, impasses e perspectivas. }\end{array}$ \\
\hline
\end{tabular}




\begin{tabular}{|l|l|}
\hline \multicolumn{1}{|c|}{ AUTOR(A) } & \\
\hline $\begin{array}{l}\text { ANO } \\
2017\end{array}$ & $\begin{array}{l}\text { TESE formação integrada omnilateral: fundamentos e práticas no Instituto Federal de Goiás } \\
\text { a partir do proeja. }\end{array}$ \\
\hline $\begin{array}{l}\text { PENA, G. A. de C. } \\
2014\end{array}$ & $\begin{array}{l}\text { Docência na educação profissional e tecnológica: conhecimentos, práticas e desafios de } \\
\text { professores de cursos técnicos na Rede Federal. }\end{array}$ \\
\hline $\begin{array}{l}\text { ALEM, N. H. } \\
2017\end{array}$ & $\begin{array}{l}\text { O ensino de história nos espaços de formação técnica e profissional: o caso do Instituto } \\
\text { Federal da Bahia/Campus Salvador (2004-2015). }\end{array}$ \\
\hline $\begin{array}{l}\text { MELILLO, C. R. } \\
2017\end{array}$ & $\begin{array}{l}\text { A dualidade na formação no ensino profissionalizante em um ambiente de aprendizagem } \\
\text { de modelagem matemática. }\end{array}$ \\
\hline
\end{tabular}

Fonte: SILVEIRA, MARTINS, 2019.

Também na CAPES, acessou-se o Portal de Periódicos, o qual foi lançado no ano de 2000, com o objetivo de fortalecer a democratização do acesso online à informação científica destinado aos Programas de Pós-graduação. Na consulta de bases de dados de periódicos da CAPES/MEC, foram selecionados trabalhos publicados no período de 2014 a 2018, a partir dos descritores "práticas pedagógicas integradoras" e foram encontrados 48 resultados. Destes, cinco convergiam com a pesquisa que está sendo desenvolvida. O Quadro 2 apresenta os respectivos autores, título do artigo, revista e ano de publicação.

Quadro 2 - Relação dos artigos encontrados no Portal de Periódicos CAPES/MEC, no período de 2014 - 2018

\begin{tabular}{|c|c|c|}
\hline $\operatorname{AUTOR}(\mathbf{A})$ & ARTIGO & REVISTA/ANO \\
\hline $\begin{array}{l}\text { SANTOS, F. A. A.; SANTOS, } \\
\text { J. D.; PROFESSOR, V. P., } \\
\text { SILVA, A. R. }\end{array}$ & $\begin{array}{l}\text { Práticas pedagógicas integradoras no ensino } \\
\text { médio integrado. }\end{array}$ & $\begin{array}{l}\text { HOLOS, 2018, vol.34(6), } \\
\text { p.185-199. }\end{array}$ \\
\hline $\begin{array}{l}\text { ARAÚJO, R. M. de L.; } \\
\text { FRIGOTTO, G. }\end{array}$ & Práticas pedagógicas e ensino integrado. & $\begin{array}{l}\text { Educação em Questão, } \\
\text { 2015, Vol.52(38), p.61-80. }\end{array}$ \\
\hline $\begin{array}{l}\text { HENRIQUE, A. L. } \quad \text { S.; } \\
\text { NASCIMENTO, J. M. N. }\end{array}$ & $\begin{array}{l}\text { Sobre práticas integradoras: um estudo de ações } \\
\text { pedagógicas na educação básica. }\end{array}$ & $\begin{array}{l}\text { HOLOS, 2015, Vol.31(4), } \\
\text { p.63-76. }\end{array}$ \\
\hline BUSS, C. da S. & $\begin{array}{l}\text { Origens, concepções e caminhos para a prática } \\
\text { pedagógica interdisciplinar. }\end{array}$ & $\begin{array}{l}\text { Thema, 2016, Vol.13(2), } \\
\text { p.68-79. }\end{array}$ \\
\hline $\begin{array}{l}\text { RODRIGUES, } \quad \text { D. } \quad \text { D.; } \\
\text { ARAÚJO, M. C. P. de. }\end{array}$ & $\begin{array}{l}\text { A integração curricular na concepção dos } \\
\text { docentes do curso técnico em agropecuária } \\
\text { integrado ao ensino médio. }\end{array}$ & $\begin{array}{lr}\text { Gondola: } & \text { Ensenanza } \\
\text { Aprendizaje de las } \\
\text { Ciencias, Jan-Jun 2017, } \\
\text { Vol.12(1), p.13-2. }\end{array}$ \\
\hline
\end{tabular}

Fonte: SILVEIRA, MARTINS, 2019

Dando continuidade a essa busca, dessa vez no Programa de Pós-graduação em Currículo e Gestão da Escola Básica (PPEB) da Universidade Federal do Pará, encontrou-se o Grupo de Estudos e Pesquisa sobre Trabalho e Educação (GEPTE), coordenado pelo Prof. Dr. Ronaldo de Lima Araújo. O GEPTE tem o ano de 2001 como início das suas atividades e tem constituído-se como referência no norte do Brasil nos estudos relacionados ao trabalho e educação. Na página eletrônica do grupo, o GEPTE: 
[... tem se ocupado de pesquisas e discussões relativas à área de trabalho e educação, tendo sido mais presente no Grupo o desenvolvimento de ações de pesquisa focadas no ensino médio, na educação profissional, nas políticas educacionais brasileiras de formação de trabalhadores, juventudes e sobre saberes de trabalhadores, mas outros temas da área de trabalho e educação também são tratados (UFPA, 2018, texto digital).

Dentre as produções desse grupo, destaca-se o relatório de pesquisa divulgado no ano de 2010, intitulado "As práticas formativas em educação profissional no Estado do Pará: em busca de uma didática da educação profissional". Nesse documento foi publicado o resultado de dois anos de pesquisa (2008-2009). Esse relatório centralizou sua investigação nas seguintes fontes: a) três veículos de comunicação, que tratam da área de trabalho e educação e discutem a prática pedagógica, com destaque em três categorias básicas da didática, a saber: objetivos de ensino, conteúdos de ensino e metodologia de ensino e de avaliação; b) entrevistas com integrantes de quatro instituições que ofertam a educação profissional no Pará, entre elas o Instituto Federal do Pará, Campus Castanhal. Como resultado da pesquisa, Araújo (2010, p. 13) evidencia que ainda

\begin{abstract}
[...] prevalece o tradicionalismo pedagógico [...]. Quanto aos procedimentos metodológicos e às estratégias de organização curricular e de avaliação, verificamos que nas instituições elas assemelham-se, mesmo naquelas em que existam tentativas de efetivação de um ensino integrado, [...] Quanto aos procedimentos metodológicos e às estratégias de organização curricular e de avaliação, verificamos que nas instituições elas assemelham-se, mesmo naquelas em que existam tentativas de efetivação de um ensino integrado, não sendo, portanto este o fator decisivo e distintivo de práticas orientadas pela lógica do mercado ou dos trabalhadores. Do ponto de vista das finalidades, contudo, ficaram claras a existências de diferenças essenciais. [...] e permitem considerar que mesmo as questões técnicas das práticas pedagógicas são definidas, explicadas e entendidas em função dos projetos políticofilosóficos aos quais elas se assentam e se articulam. Como não se pode apartar a dimensão pedagógica da dimensão ético-política, compreende-se que um projeto de ensino integrador pressupõe a edificação de uma práxis revolucionária, não sendo esta uma questão curricular, mas fundamentalmente política e filosófica. Esse aspecto depende muito mais dos projetos institucionais e da postura ideológica que os profissionais da educação profissional assumem frente à realidade, do que dos procedimentos didático-curriculares utilizados. Estes são necessários, mas não têm força estruturante de práticas formativas.
\end{abstract}

Assim, destaca-se a importância deste grupo de pesquisa e dos relevantes trabalhos que têm sido por ele desenvolvidos com financiamento da CAPES e CNPq. Nesse grupo, também foram identificadas duas dissertações (SANTOS, 2008; COSTA, 2012) que tomam como objeto de estudo o currículo integrado e as práticas pedagógicas no IFPA. O Quadro 3 apresenta a síntese das dissertações mapeadas no referido grupo. 
Quadro 3 - Demonstrativo das dissertações mapeadas no GEPTE que tratam sobre o ensino médio integrado e tem como lócus o IFPA

\begin{tabular}{|l|l|l|}
\hline \multicolumn{1}{|c|}{ AUTORA/ANO } & TÍTULO DA DISSERTAÇÃO & \multicolumn{1}{|c|}{ OBJETIVO GERAL } \\
\hline COSTA, A. M. R. 2012 & $\begin{array}{l}\text { Integração do Ensino Médio e } \\
\text { técnico: percepção de alunos do } \\
\text { IFPA/Castanhal. }\end{array}$ & $\begin{array}{l}\text { Analisar a partir da percepção dos } \\
\text { alunos, do terceiro ano do curso técnico } \\
\text { em agropecuária integrado do } \\
\text { IFPA/Castanhal, se as estratégias de } \\
\text { ensino praticadas pelos professores } \\
\text { estão possibilitando operacionalizar a } \\
\text { integração do ensino médio com a } \\
\text { educação profissional. }\end{array}$ \\
\hline $\begin{array}{l}\text { SANTOS, R. de B. L. dos. } \\
2008\end{array}$ & $\begin{array}{l}\text { Esboços de Leonardos: a a de } \\
\text { experiência da forma integrada de } \\
\text { ensino profissional no CEFET/PA. }\end{array}$ & $\begin{array}{l}\text { Conhecer a interação curricular entre o } \\
\text { ensino médio e técnico na forma } \\
\text { integrada do curso de mecânica do } \\
\text { CEFET-PA. }\end{array}$ \\
\hline
\end{tabular}

Fonte: SILVEIRA, MARTINS, 2019.

Dentre os trabalhos, destaca-se a dissertação de Santos (2008) que, ao investigar o currículo do ensino médio e técnico na forma integrada do Curso de Mecânica do Centro Federal de Educação Tecnológica do Pará (CEFET/PA), concluiu que o referido curso tendenciou ao pragmatismo, visto que priorizava as disciplinas técnicas em detrimento das de formação geral, reafirmando a educação dual. Além disso, a pesquisa destaca que "[...] tal situação adveio do pouco referencial legal e teórico do campo, desconhecimento entre áreas, devido à pouca participação da comunidade e planejamento dos professores [...]" (SANTOS, 2008, p. 12).

Por último, selecionou-se também uma obra organizada por Araújo e Silva (2017), a qual foi lançada no "I Seminário Nacional do Ensino Médio Integrado", que reúne relevantes trabalhos de pesquisa sobre o currículo integrado na Rede Federal, em diferentes estados do Brasil. Para a composição do livro, realizou-se uma chamada pública que resultou na seleção de artigos sobre o ensino médio integrado. O evento foi organizado no ano de 2017, em Brasília, pelo Fórum de Dirigentes de Ensino (FDE) e pela Câmara de Ensino do Conselho Nacional das Instituições da Rede Federal de Educação Profissional, Científica e Tecnológica (CONIF).

Ainda sobre o livro, este é composto por 569 páginas e reúne 35 artigos, resultado de pesquisas desenvolvidas. Após a leitura e identificação dos artigos que poderiam ser mais significativos para a presente pesquisa, observou-se que 18 deles problematizam o currículo integrado e as práticas pedagógicas integradoras nos diferentes Campi dos Institutos Federais de Educação (Quadro 4).

Quadro 4 - Relação dos artigos selecionados que tratam especificamente sobre currículo integrado e práticas pedagógicas

\begin{tabular}{|l|l|c|}
\hline \multicolumn{1}{|c|}{ AUTORES } & \multicolumn{1}{|c|}{ ARTIGOS } & $\begin{array}{c}\text { INSTITUTO } \\
\text { FEDERAL }\end{array}$ \\
\hline $\begin{array}{l}\text { PIUNTI, J.; SOUZA, A. X. } \\
\text { de; HORTA, P. }\end{array}$ & $\begin{array}{l}\text { Integração curricular organizada por “células” em “trilhas } \\
\text { formativas": uma experiência de criação colaborativa. }\end{array}$ & $\begin{array}{c}\text { IFSP } \\
\text { Campus } \\
\text { Sertãozinho }\end{array}$ \\
\hline SOBRINHO, S. C. & $\begin{array}{l}\text { Diretrizes institucionais e a perspectiva da integração } \\
\text { curricular no IF Farroupilha. }\end{array}$ & IF Farroupilha \\
\hline
\end{tabular}




\begin{tabular}{|c|c|c|}
\hline AUTORES & ARTIGOS & $\begin{array}{l}\text { INSTITUTO } \\
\text { FEDERAL }\end{array}$ \\
\hline $\begin{array}{l}\text { SILVA, S. P. da; VIROTE, } \\
\text { Cláudio. }\end{array}$ & $\begin{array}{l}\text { Currículo integrado no IF Goiano: possibilidades e } \\
\text { desafios. }\end{array}$ & IF GOIANO \\
\hline $\begin{array}{l}\text { SILVA-PEREIRA, L. C.; } \\
\text { SANTOS, J. R. A. dos; } \\
\text { OLIVEIRA NETO, M. G. } \\
\text { de. }\end{array}$ & $\begin{array}{l}\text { Metodologias integradoras na educação profissional: } \\
\text { construindo a ponte entre a base comum e as disciplinas } \\
\text { técnicas no ensino técnico integrado. }\end{array}$ & $\begin{array}{c}\text { IFPA } \\
\text { Campus Itaituba }\end{array}$ \\
\hline $\begin{array}{l}\text { DÁLIA, J. de } \text { M. } \quad \text { T.; } \\
\text { FRAZÃO, G. A. }\end{array}$ & $\begin{array}{l}\text { Para além do ensino integrado: experiências, possibilidades } \\
\text { e desafios da articulação entre ensino, pesquisa e extensão } \\
\text { no currículo. }\end{array}$ & $\begin{array}{l}\text { IFF } \\
\text { Campus } \\
\text { Avançado de } \\
\text { Cambuci }\end{array}$ \\
\hline $\begin{array}{l}\text { Braga, A. H.; MONTEIRO, } \\
\text { E. A. M.; SANTOS, M. M. } \\
\text { dos; CUNHA, F. B. da. }\end{array}$ & $\begin{array}{l}\text { Projeto integrador: análise de uma experiência no IF } \\
\text { Goiano Campus Ceres. }\end{array}$ & $\begin{array}{c}\text { IF Goiano } \\
\text { Campus Ceres }\end{array}$ \\
\hline $\begin{array}{ll}\text { BEVILAQUA, } & \text { D. } \\
\text { SILVA, R. S. da. } & \end{array}$ & $\begin{array}{l}\text { Integrando disciplinas entre os núcleos definidos na } \\
\text { resolução CNE/CEB N } \mathrm{N}^{\mathrm{0}} \text { 06/2012: uma experiência de } \\
\text { práticas integradoras no IFAM/Campus Manacapuru. }\end{array}$ & $\begin{array}{c}\text { IFAM } \\
\text { Campus } \\
\text { Manacapuru }\end{array}$ \\
\hline FERREIRA, F. da S. & $\begin{array}{l}\text { Docentes, professores e currículo do ensino médio } \\
\text { integrado: cenas em análise. }\end{array}$ & $\mathrm{CEFET/RJ}$ \\
\hline SILVA, R. M. da. & Currículo integrado uma proposta em construção. & $\begin{array}{c}\text { IFMT } \\
\text { Campus Sorriso }\end{array}$ \\
\hline SANTOS, J. de A. P. & $\begin{array}{l}\text { Do ensino integrado ao currículo integrado: relação entre } \\
\text { múltiplo e uno. }\end{array}$ & $\begin{array}{l}\text { IFBA Campus } \\
\text { Eunápolis }\end{array}$ \\
\hline MEDEIROS, L. F. R. de. & $\begin{array}{l}\text { Avanços e desafios nos cursos Proeja do Instituto Federal } \\
\text { Goiano Campus Rio Verde. }\end{array}$ & $\begin{array}{l}\text { IFG } \\
\text { Campus } \\
\text { Rio Verde }\end{array}$ \\
\hline $\begin{array}{l}\text { MIRANDA, P. R. de; } \\
\text { FONSECA, M. da C. F. R. }\end{array}$ & 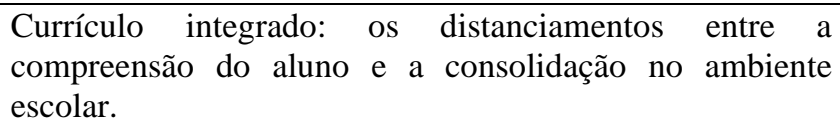 & IFSUDESTE/MG \\
\hline $\begin{array}{l}\text { REZENDE, A.; MOURA, } \\
\text { B. dos S. P. }\end{array}$ & $\begin{array}{l}\text { Nos estreitos limites a que nos coagem o mercado de } \\
\text { trabalho e o currículo escolar, ainda, podemos nos mexer: } \\
\text { práxis docente no contexto do ensino médio integrado na } \\
\text { modalidade de EJA. }\end{array}$ & IFES \\
\hline $\begin{array}{l}\text { SILVA, D. A. da; LEITE, J. } \\
\text { F.; FEIJÓ, G. V.; } \\
\text { FERREIRA, M. R. G. }\end{array}$ & $\begin{array}{l}\text { Reflexões sobre a implantação do curso técnico em eventos } \\
\text { integrado ao ensino médio no IFB. }\end{array}$ & IFB \\
\hline $\begin{array}{l}\text { PAULON, A. C.; VIEIRA, } \\
\text { D. P. P. }\end{array}$ & $\begin{array}{l}\text { A química e a história em suas relações no século XX: um } \\
\text { caso de projeto Interdisciplinar na sala de aula. }\end{array}$ & $\begin{array}{c}\text { IFRJ } \\
\text { Campus Rio de } \\
\text { Janeiro }\end{array}$ \\
\hline $\begin{array}{l}\text { CURI, L. M; GALVÃO, L. } \\
\text { L. C. }\end{array}$ & Atividades integradoras: inovação no integrado. & $\begin{array}{c}\text { IFTM } \\
\text { Campus } \\
\text { Patrocínio }\end{array}$ \\
\hline
\end{tabular}




\begin{tabular}{|l|l|c|}
\hline \multicolumn{1}{|c|}{ AUTORES } & ARTIGOS & $\begin{array}{c}\text { INSTITUTO } \\
\text { FEDERAL }\end{array}$ \\
\hline COSTA, J. B. da C. & $\begin{array}{l}\text { Uma proposta de integralização das disciplinas do núcleo } \\
\text { básico com as do núcleo tecnológico no curso técnico de } \\
\text { nível médio em informática na forma integrada. }\end{array}$ & $\begin{array}{c}\text { IFAM } \\
\text { Campus } \\
\text { Manacapuru }\end{array}$ \\
\hline $\begin{array}{l}\text { SILVA, J. D. F. da; } \\
\text { PEREIRA, J. M. S. }\end{array}$ & Proeja e currículo integrado: um caminho em construção. & IFC \\
& & $\begin{array}{c}\text { Campus } \\
\text { Camboriú }\end{array}$ \\
\hline
\end{tabular}

Fonte: Elaborado pelas autoras, 2019.

A obra "Ensino médio integrado no Brasil: fundamentos, práticas e desafios", organizada por Araújo e Silva (2017), é uma importante fonte de leitura, consulta e conhecimento de diferentes experiências sobre o ensino médio integrado na Rede Federal. Constitui-se como "[...] uma análise coletiva dos desafios apresentados no contexto das transformações previstas na Lei № 13.415, de 16 de fevereiro de 2017' (FERREIRA, 2017, p. $4)$.

\section{Considerações Finais}

Após pesquisa em diferentes bases de dados, salienta-se a importância de investigar especificamente o currículo e as práticas pedagógicas integradoras. Isso potencializa o estudo e possibilita novos olhares sobre a práxis do ensino técnico integrado ao ensino médio nas instituições federais de ensino, aspectos relevantes na presente pesquisa.

A partir do mapeamento realizado, evidencia-se a necessidade de novas pesquisas e aprofundamento sobre a questão da integração curricular nos Institutos Federais de Educação, haja vista que estes têm buscado construir caminhos para o fortalecimento do ensino técnico integrado ao ensino médio como proposta para uma formação integral, que vise à superação do ensino instrucional, voltado apenas para o mercado de trabalho.

De modo geral, as pesquisas indicam que é possível diversas práticas pedagógicas traduzirem a integração curricular sob diferentes perspectivas teóricas, e que muitas alternativas foram evidenciadas em variadas experiências pedagógicas. Tais evidências demonstram as múltiplas possibilidades da práxis integradora do currículo, o que possibilita refletir sobre o idealizado e o realizado na busca coletiva, que indiquem avanços e contradições na concretude do sentido da integração curricular.

Assim, as propostas do currículo integrado demandam reflexões qualificadas, que possam subsidiar aperfeiçoamentos na prática pedagógica e, ao mesmo tempo, construir uma proposta de formação aos adolescentes e jovens brasileiros que considere não somente a formação técnica direcionada à formação de mão de obra, mas a compreensão do processo histórico, a amplitude do mundo do trabalho e as diferentes dimensões do ser humano.

\section{Referências}

ARAÚJO, Adilson Cesar; SILVA, Cláudio Nei Nascimento da. (org.). Ensino médio integrado no Brasil: fundamentos, práticas e desafios. Brasília: Ed. IFB, 2017. 
ARAÚJO, Ronaldo Marcos de Lima, et al. As práticas formativas em educação profissional no Estado do Pará: em busca de uma didática da educação profissional. Relatório final, Belém, 2010.

BRASIL. Lei $\mathbf{n}^{\circ} \mathbf{1 3 . 4 1 5}$ de 16 de fevereiro de 2017. Altera as Leis $n^{\circ} 9.394$, de 20 de dezembro de 1996, que estabelece as diretrizes e bases da educação nacional, e 11.494, de 20 de junho 2007, que regulamenta o Fundo de Manutenção e Desenvolvimento da Educação Básica e de Valorização dos Profissionais da Educação, a Consolidação das Leis do Trabalho - CLT, aprovada pelo Decreto-Lei $n^{\circ} 5.452$, de $1^{\circ}$ de maio de 1943, e o Decreto-Lei $n^{\circ} 236$, de 28 de fevereiro de 1967; revoga a Lei $n^{\circ}$ 11.161, de 5 de agosto de 2005; e institui a Política de Fomento à Implementação de Escolas de Ensino Médio em Tempo Integral. Brasília, DF: Presidência da República, 2017. Disponível em:

http://www.planalto.gov.br/ccivil_03/_Ato2015-2018/2017/Lei/L13415.htm . Acesso em: 20 ago. 2018.

BRASIL. Ministério da Educação. Resolução nº 6, de 20 de setembro de 2012. Define Diretrizes Curriculares Nacionais para a Educação Profissional Técnica de Nível Médio. Brasília, DF: Conselho Nacional de Educação, 2012. Disponível em: http://portal.mec.gov.br/index.php?option=com_docman\&view=download\&alias=11663rceb006-12-pdf\&category_slug=setembro-2012-pdf\&Itemid=30192. Acesso em: 18 out. 2018.

BRASIL. Lei 11.892, de 29 de dezembro de 2008. Institui a Rede Federal de Educação Profissional, Científica e Tecnológica, cria os Institutos Federais de Educação, Ciência e Tecnologia, e dá outras providências, Brasília, DF: Presidência da República, 2008.

Disponível em: http://www2.camara.leg.br/legin/fed/lei/2008/lei-11892-29-dezembro-2008585085-normaatualizada-pl.pdf . Acesso em: 19 jul. 2018.

BRASIL. Ministério da Educação. Parâmetros curriculares nacionais: ensino médio. Brasília, Brasília, DF: Secretaria de Educação Média e Tecnológica, 1999.

BRASIL. Lei $\mathbf{N}^{0}$ 9.394, de 20 de dezembro de 1996. Estabelece as diretrizes e bases da educação nacional. Brasília, DF, Ministério da Educação, 1996. Disponível em: http://www.planalto.gov.br/ccivil_03/LEIS/L9394.htm . Acesso em: 10 set. 2018.

CANDAU, Vera. (Org.) A didática em questão. Petrópolis: Editora Vozes, 2007.

CAPES. Ministério da Educação. Catálogo de teses e dissertações. Disponível em: https://catalogodeteses.capes.gov.br/catalogo-teses/\#!/. Acesso em: 7 jan. 2019.

CAPES. Ministério da Educação. Portal de periódicos. Disponível em: http://www.periodicos.capes.gov.br/. Acesso em: 15 fev. 2019.

CIAVATTA, Maria; RAMOS, Marise. Ensino médio integrado. In: CALDART, Roseli Salete et al (org). Dicionário da Educação do campo. São Paulo: Escola Politécnica de Saúde Joaquim Venâncio, Expressão Popular, 2012. 
CIAVATTA, Maria; RAMOS, Marise. Ensino Médio e Educação Profissional no Brasil Dualidade e fragmentação. Revista Retratos da Escola, Brasília, v. 5, n. 8, p. 27-41, jan./jun. 2011. Disponível em: http//www.esforce.org.br. Acesso em: 07 maio 2018.

COSTA, Ana Maria Raiol da. Integração do ensino médio e técnico: percepções de alunos do Instituto Federal de Educação, Ciência e Tecnologia do Pará - IFPA/Campus Castanhal. 2012. 122f. Dissertação. (Mestrado em Educação) - Universidade Federal do Pará, Belém, 2012.

FERREIRA, Francisco Roberto Brandão. Apresentação. In: ARAÚJO, Adilson Cesar; SILVA, Cláudio Nei Nascimento da. (orgs.). Ensino médio integrado no Brasil: fundamentos, práticas e desafios. Brasília: Ed. IFB, 2017.

FRANCO, Luiz Antonio Carvalho. A escola e o trabalho e o trabalho da escola. São Paulo: Cortez: Autores Associados, 1988.

FRANCO, Maria Amélia Santoro. Práticas pedagógicas nas múltiplas redes educativas. In: LIBÂNEO, Carlos; ALVES, Nilda (Org.). Temas de pedagogia: diálogos entre didática e currículo. São Paulo: Cortez, 2012.

FRIGOTTO, Gaudêncio; CIAVATTA, Maria; RAMOS, Marise. O trabalho como princípio educativo no projeto de educação integral de trabalhadores - excertos. Disponível em: http://redeescoladegoverno.rs.gov.br/upload/1392215839_O\%20TRABALHO\%20COMO\%2 0PRINC\%C3\%8DPIO\%20EDUCATIVO\%20NO\%20PROJETO.pdf . Acesso em: 15 jun. 2017.

FRIGOTTO, Gaudêncio; CIAVATTA, Maria; RAMOS, Marise (Org.). Ensino Médio integrado: concepções e tradições. São Paulo: Cortez, 2005.

KONDER, Leandro. $O$ futuro da filosofia da práxis: o pensamento de Marx no século XXI. Rio de Janeiro: Paz e Terra,1992.

KUENZER, Acácia Zeneida. Da dualidade assumida à dualidade negada; o discurso da flexibilização justifica a inclusão excludente. Educação e Sociedade, São Paulo, v. 28, 2007.

KUENZER, Acácia Zeneida (Org.). Ensino Médio: construindo uma proposta para os que vivem do trabalho. 6. ed. São Paulo: Cortez, 2009.

RAMOS, Marise. Concepção do ensino médio integrado. Trabalho apresentado no Seminário da Secretaria de Educação do Estado do Pará, [Pará, Belém], 2008. Disponível em: http://forumeja.org.br/go/sites/forumeja.org.br.go/files/concepcao_do_ensino_medio_integrad o5.pdf . Acesso em: 14 jan. 2019.

RAMOS, Marise. Práxis e pragmatismo: referências contrapostas dos saberes profissionais. In: SÁ, Maria Roseli Gomes Brito; FARTES, Vera Lúcia Bueno. Currículo, formação e saberes profissionais: a (re) valorização epistemológica da experiência. Salvador: EDUFBA, 2010 . 
RAMOS, Marise. Prefácio. In: CAIRES, Vanessa Guerra; OLIVEIRA, Maria Auxiliadora Monteiro. Educação profissional brasileira: da colônia ao PNE 2014-2024. Petrópolis: Vozes, 2016.

SANTOS, Rosineide de Belém Lourinho dos. Esboço de leonardos: a experiência da forma integrada de ensino profissional do CEFET-PA. 2008. 155f. Dissertação (Mestrado em Educação) - Universidade Federal do Pará, Belém, 2008.

SAVIANI, Dermeval. Pedagogia Histórico-Crítica: primeiras aproximações. 11. ed. rev. São Paulo: Autores associados, 2013.

SAVIANI, Dermeval. História das ideias pedagógicas no Brasil. 4. ed. Campinas: Autores Associados, 2019.

SAVIANI, Dermeval. Trabalho e educação: fundamentos ontológicos e históricos. Revista Brasileira de Educação, Rio de Janeiro, v.12, n.34, p.152-165, 2007. Disponível em: http://www.scielo.br/scielo.php?pid=S141324782007000100012\&script=sci_abstract\&tlng=pt . Acesso em: 10 jun. 2019.

PEREIRA, L. C. S.; SANTOS, J. R. A. dos; OLIVEIRA NETO, M. G. de. Metodologias integradoras na educação profissional: construindo a ponte entre a base comum e as disciplinas técnicas no ensino técnico integrado. In: ARAÚJO, Adilson Cesar; SILVA, Cláudio Nei Nascimento da. (Orgs.). Ensino médio integrado no Brasil: fundamentos, práticas e desafios. Brasília: Ed. IFB, 2017.

SIMÕES, Carlos Artexes. Juventude e Educação Técnica: a experiência na formação de jovens trabalhadores da Escola Estadual Prof. Horácio Macedo/CEFET-RJ. 2007. Dissertação (Mestrado em Educação) - Universidade Federal Fluminense, Niterói, 2007.

VÁZQUEZ, Adolfo Sánchez. Filosofia da Práxis. São Paulo: Expressão Popular, 1977.

Recebido em agosto de 2019.

Aprovado em outubro de 2019. 